\title{
Alveolar Ridge Preservation Utilizing the 'Socket-Plug' Technique
}

\author{
George Kotsakis, Nicolas Markou, Vanessa Chrepa, Vasiliki Krompa, Anastasios Kotsakis
}

\begin{abstract}
It is proven that after every extraction of one or more teeth the alveolar bone of the respective region undergoes resorption and atrophy. Therefore ridge preservation techniques are often employed after tooth extraction to limit the volume of the alveolar bone that is going to be resorbed. There are many benefits in employing a flapless ridge preservation procedure. The purpose of this article is to present the literature concerning flapless ridge preservation techniques with collagen plugs for occlusion of the socket. The term 'socket-plug technique' is introduced to include these techniques. The basic steps of the 'socket-plug technique' are:

- Atraumatic tooth extraction

- Preservation of soft tissue architecture with the flapless technique

- Placement of the appropriate biomaterials in the extraction site

- Collagen plug stabilization

A case is presented to illustrate the steps used in this technique.
\end{abstract}

Keywords: Ridge preservation, Extraction, Alveolar bone resorption, Bone graft, Dental implants.

How to cite this article: Kotsakis G, Markou N, Chrepa V, Krompa V, Kotsakis A. Alveolar Ridge Preservation Utilizing the 'Socket-Plug' Technique. Int J Oral Implantol Clin Res 2012;3(1):24-30.

\section{Source of support: Nil}

Conflict of interest: None declared

\section{INTRODUCTION}

It is well documented in the literature that following every tooth extraction resorption of the alveolar bone is triggered in the respective region. ${ }^{1,2}$ Alveolar ridge resorption is a chronic, irreversible phenomenon, which is estimated to lead to a reduction in width ranging between 2.6 and $4.6 \mathrm{~mm}$ and in height between 0.4 and 3.9 mm postextraction. ${ }^{3-5}$ The vast percentage of the alveolar bone resorption process occurs within the first 3 to 6 months postextraction, but this procedure is chronic and the alveolar bone continues to resorb even 25 years after the extractions. ${ }^{6}$ Resorption rate varies among individuals; it even fluctuates for the same individual within different periods of time. Additionally, there is a marked difference on the resorption patterns between the maxillary and the mandibular bone with sockets in the mandible being resorbed up to 4 times faster than those in the maxilla. ${ }^{4,6}$ If no actions are employed for the prevention of this phenomenon 40 to $60 \%$ of the total alveolar bone volume is lost during the first 2 to 3 years postextraction and the phenomenon continues incessantly with a rate of 0.25 to $0.5 \%$ loss per year ${ }^{7}$ (Fig. 1).

The aim of this paper is to present the data from the literature that involve flapless ridge preservation procedures with the use of collagen plugs and report their efficacy in preserving alveolar ridge dimensions. The authors have introduced the term 'socket-plug' technique to include all the variations of this commonly used technique, which are used by many clinicians in everyday practice.

\section{Review of the Literature}

Historically, the first attempt for the reasonable studying and the prevention of the resorption phenomenon had already started before $1970^{8}$ and the submerged root concept was introduced as a ridge preservation technique. ${ }^{9,10}$ Contemporary socket preservation techniques involve the placement of different biomaterials in the socket. ${ }^{5,11}$ The choice on the biomaterials that will be used is correlated to the purpose for which the technique is going to be used (Flow Chart 1). A classification concerning the purpose for the application of a ridge preservation technique was proposed by BK Bartee. ${ }^{12}$ This classification is based on the resorbability pattern of the bone graft that will be handpicked for each case. Three categories were identified as follows: ${ }^{12}$

- Long-term ridge preservation: In this case the technique is used either for pontic site development or in order to improve the stability of removable appliances.

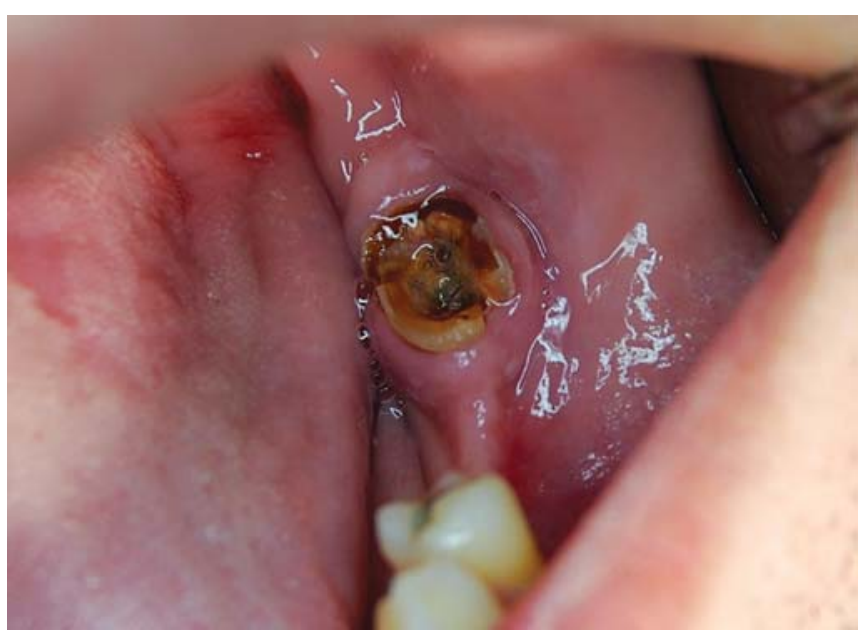

Fig. 1: Clinical view of an extraction site that was not treated with a ridge preservation technique 


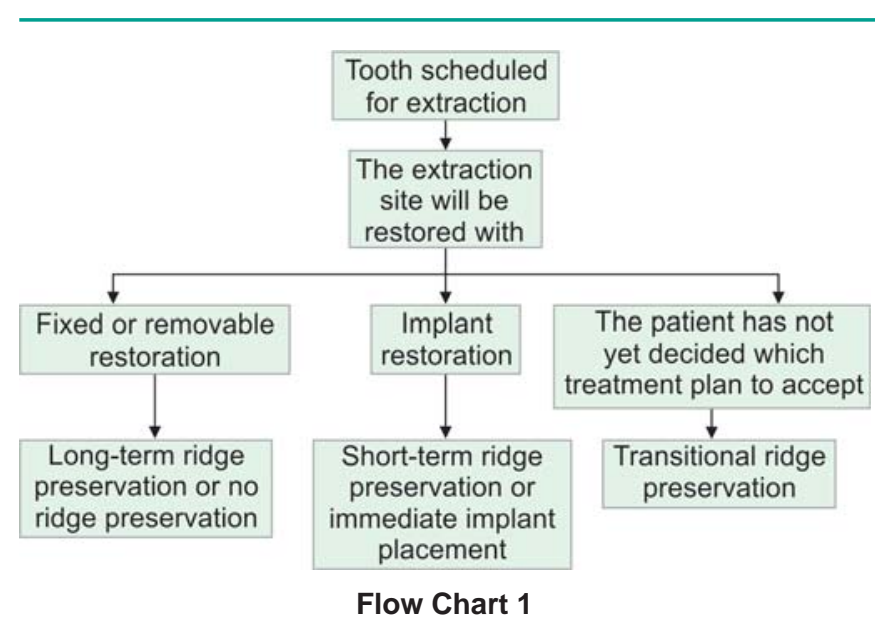

Non-resorbable materials are used for this indication and as a result the placement of implants in these sites is not favored.

- Medium-term or transitional ridge preservation: Slowly resorbable bone grafts used in ridge preservation allow for the preservation of the alveolar ridge for a protracted period of time whilst enabling the placement of an osseointegrated implant in the site after an initial healing period, even in the presence of some unresorbed graft particles. Transitional ridge preservation is indicated in cases where it is still undetermined whether the patient is going to restore the edentulism with an implant, or in cases where the patient has chosen to have an implant placed but will be unable to return and place the implant for a substantial amount of time.

- Short-term ridge preservation: The objective of this technique is to maintain the postextraction alveolar dimensions during the initial healing phase in order to allow for the placement of an implant in the shortest possible time frame.

As far as the coverage of the graft is concerned, primary soft tissue coverage with or without a membrane, sealing of the socket with a free gingival graft or a connective tissue graft and placement of a collagen plug for socket occlusion, have all been proposed. ${ }^{13-16}$ Barrier membranes have been employed showing good results in ridge preservation in a manner similar to GBR. ${ }^{17-19}$ The main drawback associated with this technique is that it requires for primary soft tissue closure. Flap advancement for primary closure causes repositioning of the mucogingival junction, displacement of the keratinized mucosa toward the crestal region and increases postoperative swelling and discomfort. ${ }^{20}$ Furthermore if the membrane undergoes secondary exposure there is a risk for infection of the graft and jeopardize of the outcome of the preservation procedure. ${ }^{21}$ The 'socket seal surgery' technique, a ridge preservation technique that does not require flap advancement was introduced to counter these procedure-inherent drawbacks. ${ }^{22}$ This minimally invasive ridge preservation procedure involves bone and soft tissue grafting. The extraction socket is filled with the bone graft of choice and then a soft tissue graft of adequate size is harvested from the palate and is placed over the graft in order to seal the socket. ${ }^{23}$ Even though the 'socket seal surgery' technique was novel in introducing a ridge preservation procedure that would not require primary flap closure, it still did not minimize the postoperative discomfort due to the graft harvesting. The 'BioCol' technique was introduced shortly afterwards using the same principles as the 'socket seal surgery', but specifically using anorganic bovine bone mineral as a bone substitute and replacing the soft tissue graft with the use of a collagen plug to occlude the socket. ${ }^{24}$ This new concept reduced postoperative discomfort to a minimum as there was no need for flap elevation or graft harvesting. After the introduction of this technique many modifications were proposed in the literature, differing either in the graft that was used ('Alloplug' technique, 'Nu-mem' technique) or in the placement of the collagen plug ('modified BioCol' technique ). ${ }^{25-27}$ The definition 'socket-plug' technique is used by the authors in this paper in order to embrace all the variations of this socket preservation technique.

\section{Socket-plug Technique}

The 'Socket-plug' technique consists of four steps:11,28

1. Atraumatic extractions after careful surgical preparation of the soft and hard tissues using periotomes: Several authors propose that a sulcular incision is done with the aid of a No. 15 or 15c scalpel, in order to dissect the crestal fibers. ${ }^{11}$ Careful curettage and debridement of the socket is done. If residual inflammatory tissue is left the bone graft may be resorbed because of the low $\mathrm{pH}$ environment of the socket and the bone regeneration process may be compromised. ${ }^{29}$ It is important that clinicians do not apply bicortical pressure on the alveolar ridge after the extraction of the tooth ${ }^{30}$ (Fig. 2).

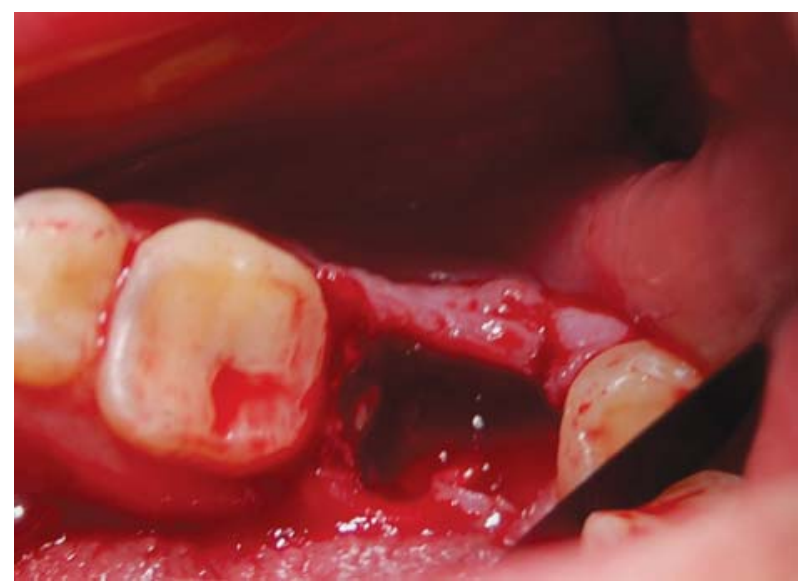

Fig. 2: Atraumatic extraction of the mandibular second molar ensures minimal damage to the alveolar bone 
2. Flapless design: Many authors have suggested various flap designs in order to establish primary closure of the socket. There is not adequate research data to clearly demonstrate that flapless socket preservation techniques are superior to techniques that involve raising a flap, but an animal study reported that the detachment of the periosteum from the buccal site of the ridge leads to an increase of the resorption rate, resulting in an increase of the ridge resorption of approximately $0.7 \mathrm{~mm} .^{31}$ Consequently there seems to be evidence to promote the idea that the use of socket preservation techniques which do not require the opening of a flap may be superior to putting effort in achieving primary closure of the socket, wherever they are indicated. Moreover, it has been shown in the literature that where a connective tissue graft, a collagen sponge or a collagen membrane was left to heal without primary closure membrane, excellent results were recorded for the preservation of the vertical dimension of the ridge showing almost complete preservation or even an increase of the height, which can be attributed to an increase in the soft tissue volume. ${ }^{28,32,33}$ The collagen sponge particularly has been found to not only protect the bone substitute, but to present hemostatic properties as well, contributing to minimal discomfort of the patient during the postsurgical period. In addition to stabilizing the blood clot, collagen plugs act as a chemotactic agents for fibroblasts. ${ }^{34}$

3. Placement of the appropriate biomaterial: Autogenous grafts are said to be the golden standard in bone grafting, because of their osteogenetic characteristics and biocompatibility. ${ }^{35}$ Common intraoral donor sites are the external oblique line, mental protuberance and maxillary tuberosity. As far as ridge preservation is concerned, the autologous graft has not been found to display any osteoinductive or osteogenetic effect. ${ }^{36,37}$ It is rapidly resorbed and it is replaced by vital bone without managing to diminish the resorptive procedure. ${ }^{36} \mathrm{~A}$ major disadvantage that is correlated with the autologous bone grafting process is patient discomfort and any advantage associated with the use of this type of graft should always be weighed against this disadvantage.

Allografts have also been employed in ridge preservation procedures, contributing positively in the dimensional stability of the postextraction socket. Allografts are slowly absorbed in socket preservation; especially the allografts that contain calcium and phosphorous salts (FDBA) are resorbed even slower than those which have been demineralized (DFDBA). ${ }^{38}$ For the first 3 to 6 months after the placement of the graft in the socket, particles of the graft are still found the socket surrounded by connective tissue and newly formed bone. ${ }^{39}$
Xenografts are used by many clinicians for ridge preservation. An animal study reported that 3 months after the use of Bio-Oss in surgically created jaw defects that were similar to postextraction resorption defects, the graft's particles remained in a percentage of approximately $30 \%$. Moreover, no osseointegration was achieved for implants placed in the regenerated defects 3 months after the placement of the xenograft. ${ }^{40}$ In another paper by Artzi et al 15 sockets were filled with inorganic bovine graft. Nine months following the graft placement, satisfactory ridge dimensional preservation was observed, but histological study revealed graft particles in connection with the newly formed bone and at a constant percentage of around $30 \%$ across the socket. Interestingly, the histomorphometric measurements revealed that the coronal part of the socket was consisting predominantly of loose connective tissue (52.4\%), followed by woven bone $(15.9 \%)$ and remaining graft particles (30\%). Descending from the coronal to the apical third of the socket, there was a marked shift of the proportion of connective tissue to the newly formed bone, with the bone being better trabeculized and occupying a percentage of $63.9 \%$ of the socket volume, while the percentage of connective tissue was decreased to $9.5 \% .{ }^{41}$ Throughout the whole socket dimension the percentage of nonabsorbed graft remained constant at about $30 \%$. The use of osseointegarted implants was predictable at 9 months after socket grafting. It can be concluded that xenografts can be used for transitional ridge preservation because of their slow resorption rate, with remaining particles being found in the socket even after 4 years. ${ }^{42}$

Alloplastic materials are a large and diverse group of bone substitutes that include hydroxyapatite, calcium phosphate, bioactive glass and calcium sulfate. Each category of alloplastic materials has a different resorption pattern ranging from the rapidly resorbing calcium sulfate that is used for short-term ridge preservation ${ }^{43}$ to condensed HA that is practically nonresorbable and is suitable for long-term ridge preservation. ${ }^{44}$ Recently there is an interest in the clinical application of novel alloplastic graft materials that have unique distribution characteristics comparing the traditional bone substituted that come in the form of particles (literature Kotsakis et al from Indian journal). One such material will be discussed in the case report below (Fig. 3).

4. Suturing: The collagen plug has a dual purpose. It is placed to prevent the wash out of the bone graft but also to induce blood clot formation and stabilization of the clot by stimulation of the platelet aggregation. ${ }^{27,34}$ For the 


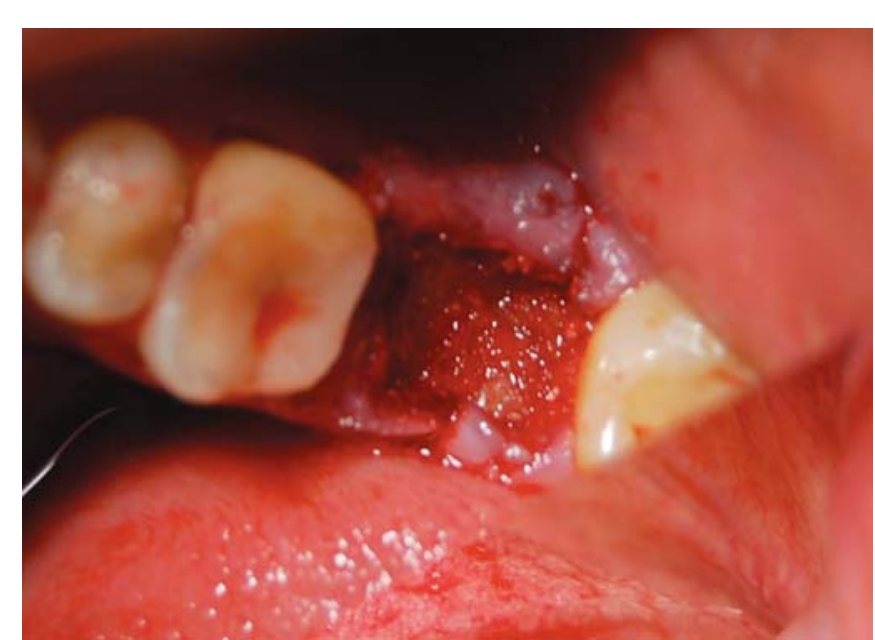

Fig. 3: The graft is placed up to the level of the bone crest

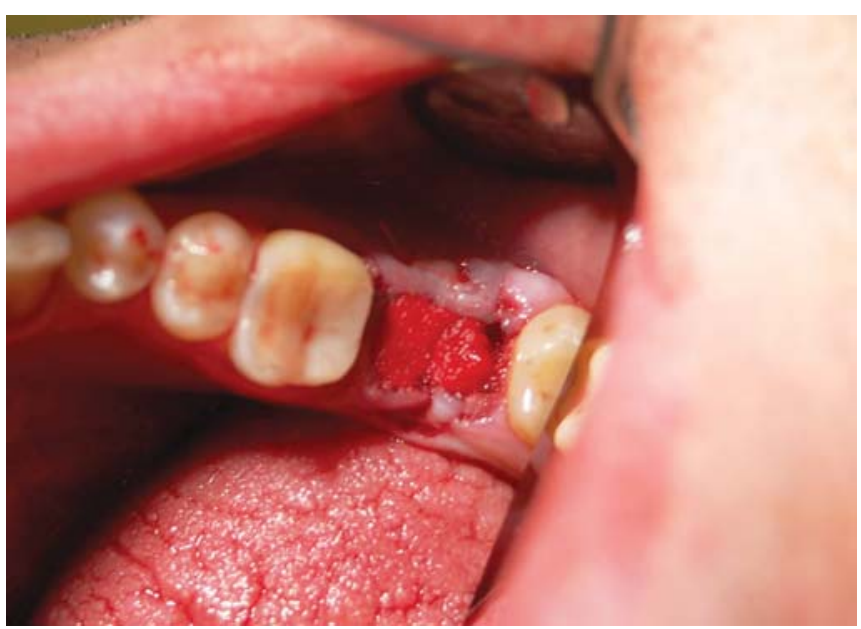

Fig. 4: The collagen plug is stabilized over the graft with a single suture. When collagen plugs are moistened with saline or blood they become very easy to shape and can be adjusted to occlude the socket

collagen plug to be stabilized over the socket suturing is done without tension in order to secure the collagen plug without distorting the gingival architecture. Preferably a single horizontal mattress suture is executed (Fig. 4).

\section{CASE PRESENTATION}

- The upper left second premolar is nonrestorable. An extraction and ridge preservation are scheduled (Fig. 5).

- The extraction is done with the least trauma possible using periotomes (Fig. 6).

- The socket is filled with a phosphosilicate graft that displays putty consistency and is easily injected into the socket saving important clinical time (Novabone putty, Novabone, Alachua, FL) (Fig. 7).

- A collagen plug is trimmed and adapted over the graft in order to occlude the socket (Fig. 8).

- The plug is stabilized with a single mattress suture. Effort is made to preserve the gingival architecture and not apply any pressure (Fig. 9).

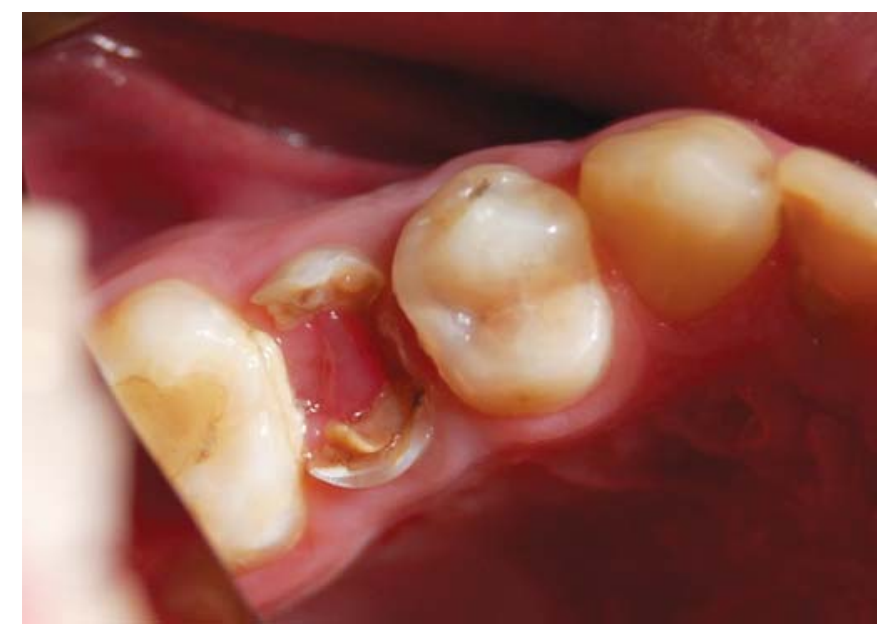

Fig. 5: Preoperative view of the nonrestorable upper left second premolar

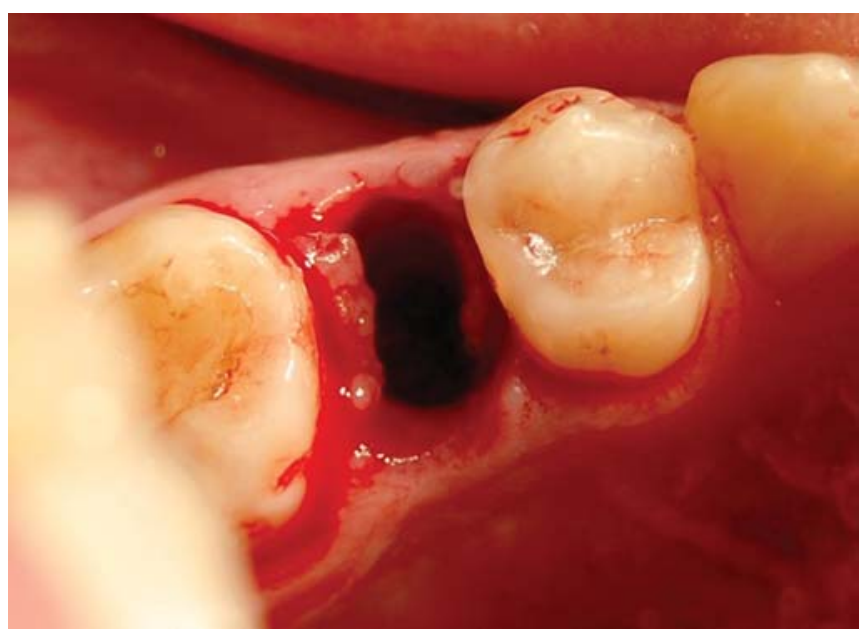

Fig. 6: The involved tooth was extracted without flap reflection

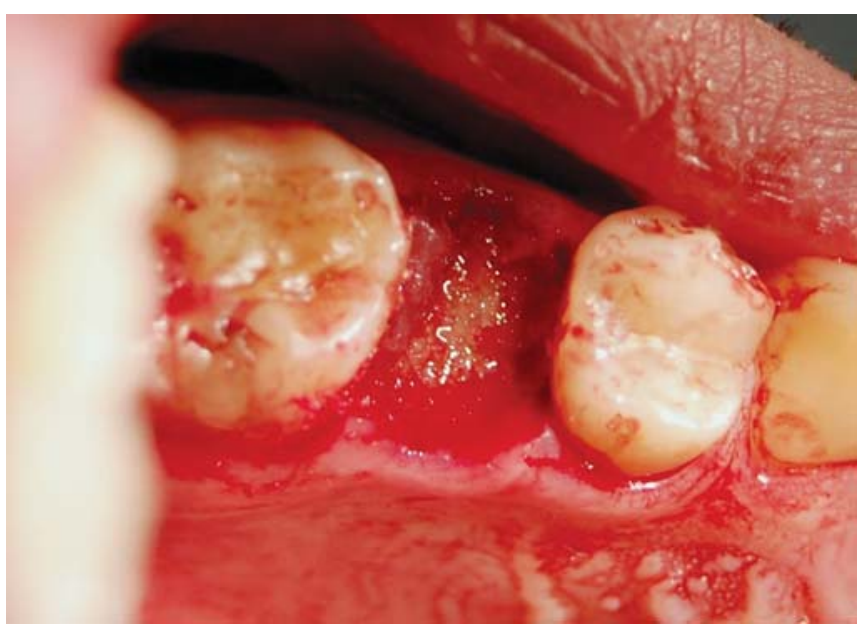

Fig. 7: The socket was filled with an alloplastic graft that displays putty consistency and is easily injected into the socket, thus saving important clinical time

- Clinical view of the healed site at 6 months postextraction. The dimensional stability of the ridge will allow for the ideal prosthetic positioning of an implant (Fig. 10). 


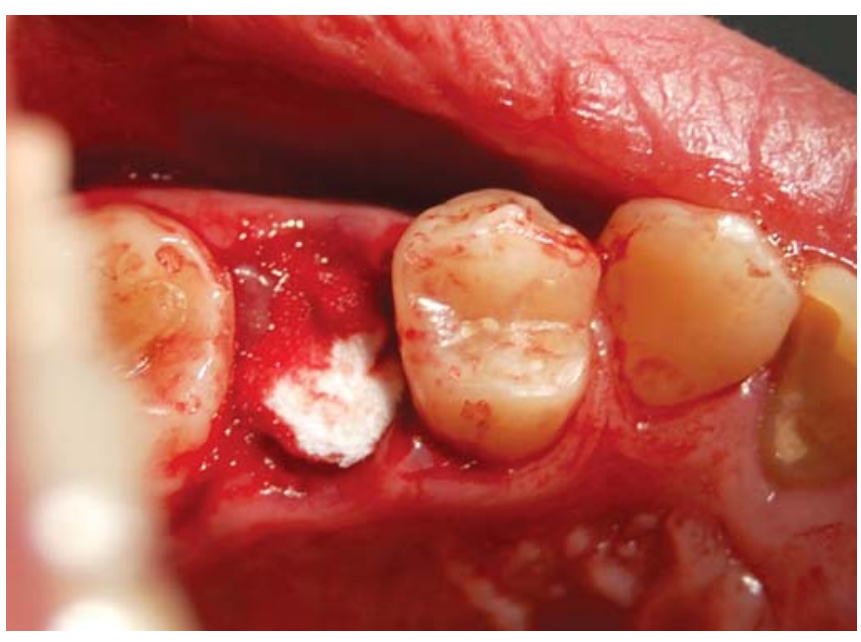

Fig. 8: A collagen plug is trimmed and adapted over the graft in order to occlude the socket

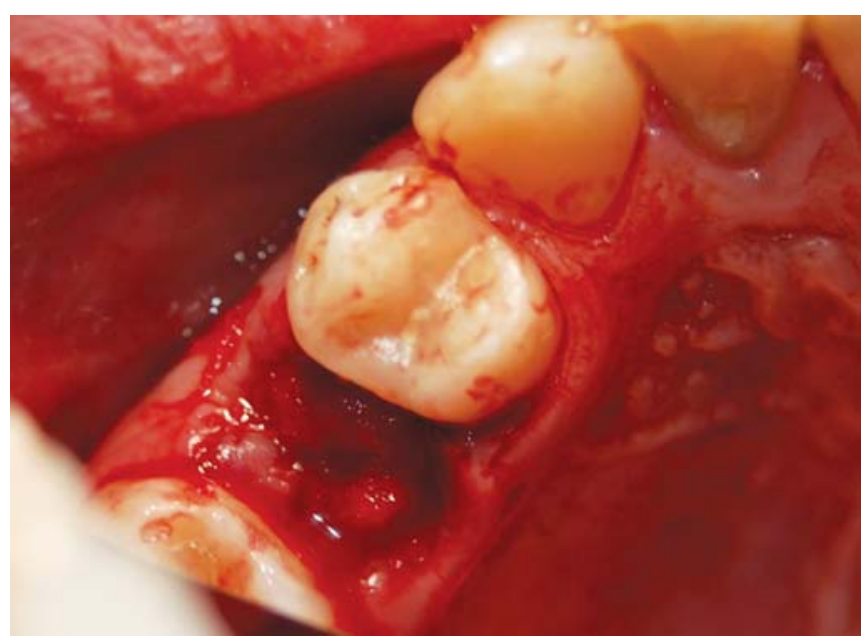

Fig. 9: The plug is stabilized with a single mattress suture. Effort is made to preserve the gingival architecture and not apply any pressure

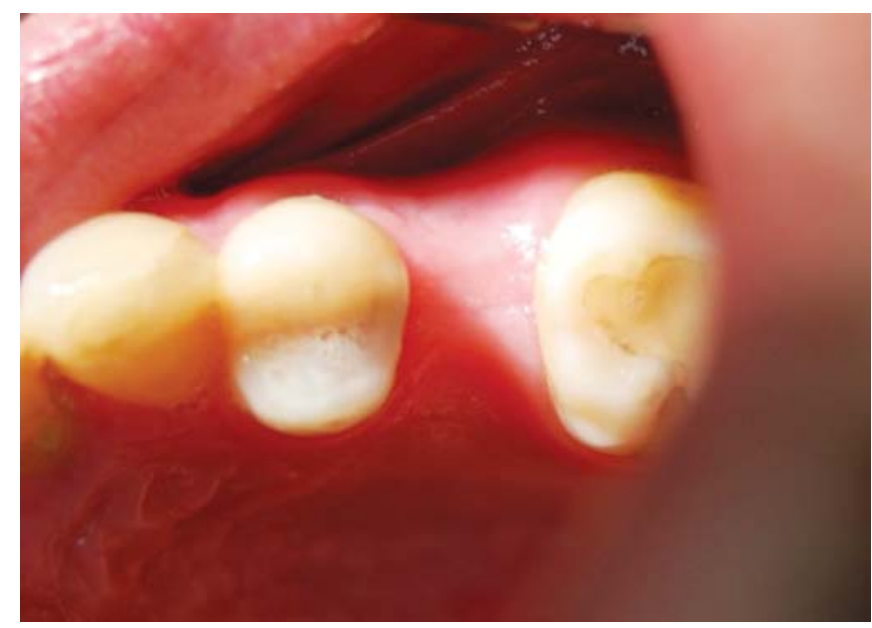

Fig. 10: Clinical view of the healed site at 6 months postextraction. The dimensional stability of the ridge will allow for the ideal restoratively-driven positioning of an implant (mirror view)

\section{DISCUSSION}

It is frequently necessary for clinicians to extract teeth for a variety of reasons, such as root fracture, periapical pathology, extensive decay or periodontal disease. Even when removal of the tooth is exercised in the most atraumatical way, vertical and horizontal bone resorption is an inevitable natural consequence. There is a loss of approximately $40 \%$ of bone height and $60 \%$ of bone width at the first 6 to 12 months postextraction. ${ }^{7,17}$ Variations of the 'socket-plug' technique have been used for more than a decade to help minimize the amount of bone loss and ensure the esthetics of the future restoration. ${ }^{24}$ The only limitation for the application of this technique is the status of the buccal plate. When the buccal plate is severely damaged a barrier membrane should be employed in order to contain the graft and prevent the soft tissue from occupying the buccal space. ${ }^{45}$ This technique is a flapless approach to ridge preservation. As a result it has certain advantages including preservation of the blood circulation, the soft tissue architecture, the hard tissue volume at the site, decreased surgical time, minimal patient comfort and accelerated recuperation. It is important to mention that the patient is enabled to resume normal oral hygiene procedures immediately after the surgery. In addition, several techniquerelated drawbacks of raising a flap on placing a membrane for ridge preservation are prevented, such as reduction of keratinized gingiva, alteration of gingival contours and migration of the mucogingival junction, which may occur during coronal displacement of the flap in an attempt to achieve primary closure. As far as the dimensional stability of the ridge with this technique is concerned, an in vivo study reported that in sockets treated with the 'socket-plug' technique, using anorganic bovine bone mineral the resorption after 3 months was limited to $14 \%$ of the initial bone width whereas the control group had a resorption of $21 \%{ }^{46}$ In another study comparing histological outcomes of the 'socket-plug' technique comparing allogenic and xenogenic bone grafts, the results showed that in the allograft socket the graft was completely integrated into the newly formed bone after 3 months of healing whereas in the anorganic bovine bone socket there was partial integration of the graft with distinguishable graft particles. ${ }^{47}$

\section{CONCLUSION}

According to the literature, the alveolar ridge resorption process can be limited. Ridge preservation requires thorough comprehension of tissue healing procedures after the extraction of one or more teeth, as well as deep knowledge of bone substitutes properties. The 'socket-plug' technique can help the clinician to provide the best possible outcome with the least patient discomfort. The results of this technique not only depend on the delicate handling of the area, but also on the resorption rate of the graft material and its replacement by mature bone capable of withstanding functional loading. 


\section{REFERENCES}

1. Ashman A, Rosenlicht J. Ridge preservation: Addressing a major problem in dentistry. Dent Today 1993;12:80-84.

2. Atwood DA. Reduction of residual ridges: A major oral disease entity. J Prosthet Dent 1971;26(3):266-79.

3. Cawood JI, Howell RA. A classification of the edentulous jaws. Int J Oral Maxillofac Surg 1988;17(4):232-36.

4. Atwood DA, Coy WA. Clinical, cephalometric and densitometric study of reduction of residual ridges. J Prosthet Dent 1971;26(3):280-95.

5. Ten Heggeler JM, Slot DE, Van der Weijden GA. Effect of socket preservation therapies following tooth extraction in nonmolar regions in humans: A systematic review. Clin Oral Implants Res Aug 2011;22(8):779-88.

6. Tallgren A. The continuing reduction of the residual alveolar ridges in complete denture wearers: A mixed-longitudinal study covering 25 years. J Prosthet Dent 1972;27(2):120-32.

7. Ashman A. Postextraction ridge preservation using a synthetic alloplast. Implant Dent 2000;9(2):168-76.

8. Atwood DA. Postextraction changes in the adult mandible as illustrated by microradiographs of midsagittal sections and serial cephalometric roentgenograms. J Prosthet Dent 1963;13: 810-24.

9. Casey DM, Lauciello FR. A review of the submerged root concept. J Prosthet Dent 1980;43:128-32.

10. Von Wowern N, Winther S. Submergence of roots for alveolar ridge preservation. A failure (4-year follow-up study). Int J Oral Surg 1981;10:247-50.

11. Wang HL, Kiyonobu K, Neiva RF. Socket augmentation: Rationale and technique. Implant Dent 2004;13:286-96.

12. Bartee BK. Extraction site reconstruction for alveolar ridge preservation. Part 1: Rationale and materials selection. J Oral Implantol 2001;27(4):187-93.

13. Sclar AG. Strategies for management of single-tooth extraction sites in esthetic implant therapy. J Oral Maxillofac Surg Sep 2004;62(9 Suppl 2):90-105.

14. Landsberg CJ. Socket seal surgery combined with immediate implant placement: A novel approach for single-tooth replacement. J Periodontics Restorative Dent Apr 1997;17(2):140-49.

15. Tal H. Autogenous masticatory mucosal grafts in extraction socket seal procedures: A comparison between sockets grafted with demineralized freeze-dried bone and deproteinized bovine bone mineral. Clin Oral Implants Res Aug 1999;10(4):289-96.

16. Bitter RN. A rotated palatal flap ridge preservation technique to enhance restorative and hard and soft tissue esthetics for tooth replacement in the anterior maxilla. Int J Periodontics Restorative Dent Apr 2010;30(2):195-201.

17. Lekovic V, Camargo PM, Klokkevold PR, Weinlaender M, Kenney EB, Dimitrijevic B, Nedic M. Preservation of alveolar bone in extraction sockets using bioabsorbable membranes. $\mathrm{J}$ Periodontol Sep 1998;69(9):1044-49.

18. Mardas N, D’Aiuto F, Mezzomo L, Arzoumanidi M, Donos N. Radiographic alveolar bone changes following ridge preservation with two different biomaterials. Clin Oral Implants Res Apr 2011;22(4):416-23.

19. Carmagnola D, Adriaens P, Berglundh T. Healing of human extraction sockets filled with Bio-Oss. Clin Oral Implants Res Apr 2003;14(2):137-43.

20. Engler-Hamm D, Cheung WS, Yen A, Stark PC, Griffin T. Ridge preservation using a composite bone graft and a bioabsorbable membrane with and without primary wound closure: A comparative clinical trial. J Periodontol Mar 2011;82(3): 377-87.

21. Verardi S, Simion M. Management of the exposure of e-PTFE membranes in guided bone regeneration. Pract Proced Aesthet Dent Mar 2007;19(2):111-17.

22. Landsberg CJ, Bichacho N. A modified surgical/prosthetic approach for optimal single implant supported crown. Part I: The socket seal surgery. Pract Periodontics Aesthet Dent Mar 1994;6(2):11-17.

23. Landsberg CJ. Implementing socket seal surgery as a socket preservation technique for pontic site development: Surgical steps revisited-a report of two cases. J Periodontol May 2008;79(5):945-54.

24. Sclar AG. Preserving alveolar ridge anatomy following tooth removal in conjunction with immediate implant placement. The Bio-Col technique. Atlas Oral Maxillofac Surg Clin North Am Sep 1999;7(2):39-59.

25. Sclar AG. Strategies for management of single-tooth extraction sites in aesthetic implant therapy. J Oral Maxillofac Surg. Sep 2004;62(Suppl 2):90-105.

26. Fowler EB, Whicker R. Modified approach to the Bio-Col ridge preservation technique: A case report. J Contemp Dent Pract. Aug 15, 2004;5(3):82-96.

27. Wang HL, Tsao YP. Mineralized bone allograft-plug socket augmentation: Rationale and technique. Implant Dent 2007;16:33-41.

28. Iasella JM, Greenwell H, Miller RL, et al. Ridge preservation with freeze-dried bone allograft and a collagen membrane compared to extraction alone for implant site development: A clinical and histologic study in humans. J Periodontol 2003;74(7):990-99.

29. Garg AK, Reddi SN, Chacon GE. The importance of asepsis in dental implantology. Implant Soc 1994;5(3):8-11.

30. Zitzmann NU, Scharer P. Oral Rehabilitation with Dental Implants.

31. Fickl S, Zuhr O, Wachtel H, Stappert CFJ, Stein JM, Hurzeler MB. Dimensional changes of the alveolar ridge contour after different socket preservation techniques. A histomorphometrical study in dogs. J Clin Periodontol 2008;35:906-13.

32. Becker W, Clokie C, Sennerby L, Urist MR, Becker BE. Histologic findings after implantation and evaluation of different grafting materials and titanium microscrews into extraction sockets: Case reports. J Periodontol 1998;69(4):414-21.

33. Vance GS, Greenwell H, Miller RL, Hill M, Johnston H, Scheetz JP. Comparison of an allograft in an experimental putty carrier and a bovine-derived xenograft used in ridge preservation: A clinical and histologic study in humans. Int J Oral Maxillofac Implants 2004;19(4):491-97.

34. Postlethwaite AE, Seyer JM, Kang AH. Chemotactic attraction of human fibroblasts to type I, II and III collagens and collagen derived peptides. Proc Natl Acad Sci USA 1978;75:871-75.

35. Damien C, Parsons JR. Bone graft and bone graft substitutes: A review of current technology and applications. J App Biomat 1991;2:187-208.

36. Becker W, Urist M, Becker BE, Jackson W, Parry DA, Bartold $\mathrm{M}$, et al. Clinical and histologic observations of sites implanted with intraoral autologous bone grafts or allografts. 15 human case reports. J Periodontol 1996;67(10):1025-33. 
37. Araújo MG, Lindhe J. Socket grafting with the use of autologous bone: An experimental study in the dog. Clin Oral Implants Res Jan 2011;22(1):9-13.

38. Wood RA, Mealey BL. Histological comparison of healing following tooth extraction with ridge preservation using mineralized vs. demineralized freeze dried bone allograft. J Periodontol Dec 2010;81(12):1765-72.

39. Beck TM, Mealey BL. Histologic analysis of healing after tooth extraction with ridge preservation using mineralized human bone allograft. J Periodontol Dec 2010;81(12):1765-72.

40. Carmagnola D, Berglundh T, Araújo M, Albrektsson T, Lindhe J. Bone healing around implants placed in a jaw defect augmented with Bio-Oss. An experimental study in dogs. J Clin Periodontol Nov 2000;27(11):799-805.

41. Artzi Z, Tal H, Dayan D. Porous bovine bone mineral in healing of human extraction sockets. Part 1: Histomorphometric evaluations at 9 months. J Periodontol 2000;71:1015-23.

42. Allegrini S Jr, Koening B Jr, Allegrini MR, Yoshimoto M, Gedrange T, Fanghaenel J, Lipski M. Alveolar ridge sockets preservation with bone grafting-review. Ann Acad Med Stetin 2008;54(1):70-81.

43. Guarnieri R, Aldini NN, et al. Medical-grade calcium sulfate hemihydrate (surgiplaster) in healing of a human extraction socket-histologic observation at 3 months: A case report. Int $\mathrm{J}$ Oral Maxillofac Implants 2005;20(4):636-41.

44. Fiorellini JP, Nevins ML. Localized ridge augmentation/ preservation. A systematic review. Ann Periodontol 2003; 8(1):321-27.
45. Misch CE. Contemporary implant dentistry (2nd ed). St Louis: Mosby Inc. 1999;462.

46. Kim YK, Yun PY, Lee HJ, Ahn JY, Kim SG. Ridge preservation of the molar extraction socket using collagen sponge and xenogenic bone grafts. Implant Dent Aug 2011;20(4):267-72.

47. Len Tolstunov, Jibin Chi. Alveolar ridge augmentation: comparison of two socket graft materials in implant cases. Compend Cont Edu, March 2011;32(2).

\section{ABOUT THE AUTHORS}

\section{George Kotsakis}

Private Practice, Krompa-Kotsakis Dental Clinic, Athens, Greece Phone: 306944292065, e-mail: gkotsakis@krompakotsakisdental.gr

\section{Nicolas Markou}

Private Practice, Krompa-Kotsakis Dental Clinic, Athens, Greece

\section{Vanessa Chrepa}

Private Practice, Krompa-Kotsakis Dental Clinic, Athens, Greece

\section{Vasiliki Krompa}

Private Practice, Krompa-Kotsakis Dental Clinic, Athens, Greece

\section{Anastasios Kotsakis}

Private Practice, Krompa-Kotsakis Dental Clinic, Athens, Greece 